\title{
“AS JANELAS VITRAIS DO SÉCULO XXI” EM MEIO $\vdots$ AMBIENTES SOCIOLINGUÍSTICOS CADA VEZ MAIS : COMPLEXOS: AS PICHAÇÓES E OS GRAFITES NA CIDADE DE JUIZ DE FORA/MG
}

\section{"THE TWENTY-FIRST CENTURY STAINED GLASS WINDOWS” IN INCREASINGLY COMPLEX SOCIOLINGUISTIC ENVIRONMENTS: GRAFFITI IN THE CITY OF JUIZ DE FORA / BRAZIL}

\author{
Mariana Schuchter Soares ${ }^{1}$ \\ Universidade Federal de Juiz de Fora \\ Ana Claudia Peters Salgado ${ }^{2}$ \\ Universidade Federal de Juiz de Fora
}

\section{RESUMO}

Este trabalho, que é parte do projeto de pesquisa $A$ mobilidade social e suas implicações na paisagem linguística de Juiz de Fora/MG, aprovado no Edital 01/2015 - Demanda Universal/Fapemig, tem como objetivo discutir questões relacionadas à mobilidade dos signos, cujas formas viajam frequentemente sem problemas, enquanto outros recursos, tais como indexicalidade, significados e valor social acabam ganhando novos contornos em novos contextos. Para isso, utilizamos as teorias de Vertovec (2007) sobre superdiversidade, de Blommaert (2010, 2012, 2013) sobre globalização e superdiversidade, e de Kroon, Jie e Blommaert (2011) sobre textos que se movem. Nesse sentido, analisamos fotografias de pichações e grafites encontrados pela cidade de Juiz de Fora/MG, buscando demonstrar como a superdiversidade, e de Kroon, Jie e Blommaert (2011) sobre textos que se movem. Nesse sentido, analisamos

1 Doutoranda em Linguística pela Universidade Federal de Juiz de Fora. E-mail: marischuchter@ yahoo.com.br

2 Professora Adjunta da Faculdade de Letras da Universidade Federal de Juiz de Fora. E-mail: ana. peters@ufjf.edu.br 
: fotografias de pichações e grafites encontrados pela cidade de Juiz de

: Fora/MG, buscando demonstrar como a superdiversidade, produto de movimentos migratórios e do desenvolvimento da tecnologia, pode ser vivenciada através de repertórios comunicativos cada vez mais diversificados.

PALAVRAS-CHAVE: globalização; superdiversidade; mobilidade dos signos; pichações e grafites.

\section{ABSTRACT}

This paper, which is part of the research project Social Mobility and its Implications for the Linguistic Landscape from Juiz de Fora/ Brazil, approved on the Notice 01/2015 - Universal Demand/Fapemig, aims to discuss issues related to mobility of signs, whose forms often travel without problems, while other features such as indexicality, meanings and social value get new contours in new contexts. Thereunto, we use theories by Vertovec (2007) about superdiversity, by Blommaert (2010, 2012, 2013) about globalization and superdiversity, and by Jie and Blommaert (2011) about text moving. In this sense, we analyze graffiti photographs found around the city of Juiz de Fora/Brazil, in order to demonstrate how superdiversity, considered a product of the migration movements and the development of technology, can be experienced through communicative repertoires increasingly diverse.

KEYWORDS: globalization; superdiversity; signs mobility; graffiti.

\section{INTRODUÇÃO}

Alastair Pennycook (2009), em seu trabalho "Landscapes and the Transgressive semiotics of graffiti", publicado no livro "Linguistic Landscape: Expanding the Scenery", organizado por Elana Shohamy e Durk Gorter, diz que os grafites podem ser concebidos como as "TwentyFirst Century stained glass windows", i.e., como "as janelas vitrais do século XXI”. O autor usa essa expressão considerando o fato de essas janelas permitirem o acesso àquilo que acontece nas ruas e, ao mesmo tempo, nas mentes dos sujeitos contemporâneos.

Ao pensarmos um pouco sobre essa analogia, é possível encontrar outros aspectos que ligam os vitrais aos grafites e, ao mesmo tempo, 
apontam para questões relevantes a este trabalho.

De acordo com Michelotti (2011, p. 27), os vitrais são objetos compostos por fragmentos de vidro, combinados e fixados por pedaços de metal fundido, em uma composição. Se ponderarmos sobre os grafites, podemos dizer que também são composições formadas por fragmentos sendo que, dessa vez, são fragmentos de língua, retirados de caldeirões de recursos linguísticos ad hoc, que diferem de pessoa para pessoa (GRABER, 2014, p. 352). Essas "piscinas" são nada menos do que os diferentes repertórios comunicativos dos agentes, combinados e fixados por processos semióticos e socioculturais que incorporam outros materiais.

Além disso, o vidro é um material altamente versátil. De acordo com Michelotti (2011, p. 27), quando em estado de fusão, ele pode ser torcido, soprado, moldado em milhares de formas, e receber as mais diversas cores. Uma vez resfriado, pode ser cortado, polido, chanfrado, esculpido, pintado. O mesmo pode-se dizer da "língua", que também é altamente "versátil", pode ser desmontada e remontada (GRABER, 2014), seus recursos podem ser movidos (vide KROON, JIE \& BLOMMAERT, 2011), "fundidos” com outros e moldados em milhares de formas, muitas vezes não convencionais - caso da lookalike language 3 (BLOMMAERT, 2012). Além disso, os recursos linguísticos presentes nos grafites expressam os mais diferentes significados atribuídos pela mobilidade e pelas mãos de seus agentes. Portanto, os fragmentos de línguas políticas presentes nos grafites também podem ser "cortados", "juntados" e "esculpidos" por aspectos ligados ao meio ambiente sociolinguístico local.

Iniciamos este artigo, portanto, a partir da perspectiva de que as línguas são móveis, fragmentáveis e adaptáveis. Tal como salienta Kroon, Jie e Blommaert (2011, p. 2), não estamos falando de um sistema com características estruturais estáveis. Estamos dizendo, na verdade, que o sistema é passível de mudanças, uma vez que pode ser modificado pelos sujeitos de acordo com o meio ambiente em que está inserido e pela mobilidade.

Esta reflexão muito nos diz sobre aspectos dos grafites e pichações de Juiz de Fora. O que acontece na cidade, neste momento da pesquisa, considerando as mais diversas e plurais manifestações linguísticas, parece

3 A grafia da expressão em inglês, cunhada por Blommaert (2012), é lookalike language. Os termos "look" e "alike" são escritos juntos. 
: refletir o que está acontecendo com/a partir da linguagem em outras partes : do mundo em tempos de superdiversidade.

Assim, na primeira seção, discutimos como recursos/fragmentos linguísticos se movem pelo mundo, envolvendo, muitas vezes, para sua compreensão, processos de decodificação e interpretação (KROON, JIE \& BLOMMAERT, 2011). Dessa forma, podemos dizer que os efeitos da globalização têm formado meio ambientes sociolinguísticos cada vez mais complexos. Na segunda seção, por sua vez, tratamos do meio ambiente sociolinguístico da cidade de Juiz de Fora, o que inclui questões locais, relacionadas ao fluxo migratório e às influências da Universidade Federal de Juiz de Fora, bem como globais, como o desenvolvimento da tecnologia. $\mathrm{Na}$ terceira seção, discutimos a diferença entre grafites e pichações no contexto da pesquisa. $\mathrm{Na}$ quarta e última seção, mostramos algumas fotografias da paisagem linguística da cidade de Juiz de Fora, bem como as analisamos, com o intuito de revelar como recursos de diferentes línguas políticas estão presentes nos grafites e nas pichações, até mesmo em forma de uma "língua que parece ser" (BLOMMAERT, 2012).

\section{Algumas questões sobre globalização, línguas fragmentadas e mobilidade}

Blommaert (2010, p. 1), em sua obra "The Sociolinguistics of Globalization", defende que estamos em tempos de globalização. Para ele, o mundo - que não é mais uma "vila", mas uma rede complexa de vilas, aldeias, cidades, bairros etc., ligados por laços materiais e simbólicos muitas vezes imprevisíveis - está em constante processo de transformação. Portanto, os sociolinguistas estudam uma língua em mudança em uma sociedade em mudança.

Ainda para o autor, parecem necessários, em meio a esta nova realidade, um novo vocabulário para descrever os eventos, fenômenos e processos, novas metáforas para representá-los e novos argumentos para explicá-los (BLOMMAERT, 2010, pp. 1-2).

A globalização pode ser pensada, segundo Rubdy e Alsagoff (2014, p. 1), como um processo multidimensional, que perpassa várias esferas de atividades, nos domínios da economia, da política, da cultura, da tecnologia, entre outras. A partir de transformações irregulares e imprevisíveis, o que parece existir, na verdade, é um complexo de processos se desenvolvendo 
de diferentes formas, velocidades e intensidades, modificando a paisagem do mundo.

Neste contexto, está também a superdiversidade, cujo termo foi cunhado por Vertovec (2006). Para ele, nas décadas mais recentes, a natureza da imigração no contexto inglês - e, como acreditamos, em outros meio ambientes em diferentes graus e nuances -, tem originado um tipo de "diversificação da diversidade", não apenas em termos de etnia e de origem dos imigrados, mas também no que se refere a "[...] uma variedade de significantes variáveis que afetam onde, como e com quem as pessoas convivem (VERTOVEC, 2006, p. 1, tradução nossa)"4. Como acreditamos, apesar de se configurar em graus variados, a superdiversidade já está por toda parte, principalmente nos centros urbanos.

Uma das consequências desta superdiversidade é o aumento da imprevisibilidade. Agora, o "outro" é uma categoria em constante fluxo, sempre em processo de mudança. Sobre esse "outro" pouco se pode supor (BLOMMAERT, 2013, p. 11). Assim, para Blommaert (2013, p. 11), a superdiversidade é guiada por três palavras-chave: mobilidade, complexidade e imprevisibilidade.

Em meio a tantas transformações estão os contatos linguísticoculturais. Esses se tornaram muito mais intensos a partir das mudanças em termos de mobilidade, o que sugere que a ideia de fronteiras linguísticas é um mero construto ideológico. Se antes as nações eram detentoras de suas "línguas" (enquanto instrumentos políticos), hoje já não o são. De acordo com Rajagopalan (2009, p. 65) sobre a língua inglesa (o que, na verdade, se encaixa em todas as línguas do mundo em tempos de superdiversidade), a língua não tem pátria, nem está delimitada a uma região geográfica.

Assim, em tempos de globalização e superdiversidade, torna-se cada vez mais difícil considerar uma sociolinguística fundamentada em um mundo social em que as pessoas continuam sempre juntas no mesmo lugar e compartilham o que conhecem de uma língua e de seu uso. Nesse mesmo contexto idealizado, atingem-se padrões de comunicação que perduram e podem ser descritos sincronicamente, em termos estruturalistas. Essa se configura como uma "visão sedentária dos seres humanos e de suas sociedades” (KROON, JIE \& BLOMMAERT, 2011, p. 1, tradução nossa).

4 [...] a variety of significant variables that affect where, how and with whom people live (VERTOVEC, 2006 , p. 1, como no original). 
É preciso, portanto, repensar algumas visões tradicionais e estereótipos : em torno daquilo que se lê, que se escreve, que se usa para a comunicação no geral, que está presente nas paisagens linguísticas dos centros urbanos. Isso porque um sociolinguista deve considerar que os recursos são móveis, assim como são as pessoas. Nesse movimento, não há lugar para modelos lineares de entendimento. De acordo com Kroon, Jie e Blommaert (2011, pp. 2-3), quando os signos viajam, suas formas se movem sem problemas, enquanto outros recursos dos signos - indexicalidade, significados, valor social etc. - nem tanto.

Nesse sentido, para Blommaert (2010, p. 3), estamos diante de uma "sociolinguística da mobilidade", cujo foco não é "língua em lugar", mas "língua em movimento", com vários frames espaços-temporais que interagem entre si. Ao pensar sobre os signos produzidos em/ pela mobilidade, podemos dizer que o acesso a frames adequados para o entendimento exige não apenas o conhecimento do meio ambiente sociolinguístico de origem, mas o conhecimento de uma economia local de símbolos e significados.

É fato que a mobilidade é a chave para a realidade do mundo de hoje. Todas as coisas são móveis, podem viajar de um lado para o outro, se não fisicamente, através do espaço virtual. Isso quer dizer que estamos em uma era dinâmica e marcada pela instabilidade, e que não há espaço para pensamentos reducionistas.

No entanto, esse movimento de recursos linguísticos não se dá para espaços vazios. De acordo com Blommaert (2010, p. 6, tradução nossa),

[...] Esses espaços são sempre de "alguém", são preenchidos por normas, expectativas, concepções do que é apropriado e normal (indexicalidade) quanto ao uso da língua e o que não é. [...] Mobilidade, sociolinguisticamente falando, é, portanto, uma trajetória através de diferentes espaços estratificados, controlados e monitorados.

Dessa forma, os recursos linguísticos móveis são absorvidos pelo meio ambiente sociolinguístico e adaptados a ele, considerando que são influenciados por grafias já existentes, formas locais de pronúncia, padrões pragmáticos ou poéticos dominantes etc. (BLOMMAERT, 2012, p. 60). A partir dessa dinamicidade, recursos específicos estão sendo misturados, buscando-se criar sentidos para os indivíduos. 


\section{O meio ambiente sociolinguístico atual da cidade de Juiz de Fora}

A cidade de Juiz de Fora está localizada na Zona da Mata do estado : de Minas Gerais, a cerca de $280 \mathrm{~km}$ da capital Belo Horizonte. Conta, hoje, com uma área de 1.435,664 $\mathrm{km}^{2} \mathrm{e}$, de acordo com o último censo demográfico realizado IBGE, no ano de 2010, possuía um total de 516.247 habitantes, com densidade demográfica de 359,59 hab/ $\mathrm{Km}^{2}$. No ano de 2013, a estimativa era de 545.942 pessoas.

Ainda de acordo com dados do IBGE, um terço da população de Juiz de Fora, em 2010, não tinha nascido na cidade. Isso representava 173.209 de 516.247 habitantes. Ainda, mais de 50.000 residentes em Juiz de Fora tinham vindo de outros estados. Esses números, conforme matéria publicada no jornal Tribuna de Minas, no dia 28 de abril de 2012, não levavam em conta a maioria dos estudantes de fora, uma vez que as pessoas que têm família em outras cidades, mas vivem em Juiz de Fora e fazem uso da rede de ensino local, normalmente são contabilizadas como habitantes dos municípios onde seus pais residem. Por isso, o número de pessoas de fora presentes no dia a dia da cidade é ainda maior.

Em 2010, Juiz de Fora já era a segunda cidade mineira em número de residentes estrangeiros, somando 1.050 pessoas. O município, que tem a característica de atrair imigrantes, contava ainda com 186 habitantes naturalizados brasileiros. Hoje, esse número com certeza é muito maior. Isso porque a cidade cresce, a cada dia, a olhos vistos. Além disso, a Universidade Federal de Juiz de Fora, junto ao governo federal, tem expandido suas políticas de intercâmbio. Vários projetos, tais como o Sisus e o Ciência sem fronteiras $^{6}$, têm dado oportunidade a mais jovens de outras localidades de ingressarem na faculdade.

5 O Sistema de Seleção Unificada (Sisu) é o sistema informatizado gerenciado pelo Ministério da Educação (MEC), a partir do qual instituições públicas de ensino superior oferecem vagas para candidatos, de todo o Brasil, participantes do Exame Nacional de Ensino Médio (Enem).

6 O programa Ciência sem Fronteiras busca promover a consolidação e a internacionalização da ciência e tecnologia, da inovação e da competitividade brasileira por meio do intercâmbio e da mobilidade internacional. A iniciativa é fruto de esforço conjunto dos Ministérios da Ciência, Tecnologia e Inovação (MCTI) e do Ministério da Educação (MEC), por meio de suas respectivas instituições de fomento - CNPq e Capes -, e Secretarias de Ensino Superior e de Ensino Tecnológico do MEC. O projeto prevê a utilização de bolsas de intercâmbio, de forma que alunos de graduação e pós-graduação possam fazer estágio no exterior, bem como atrair pesquisadores do exterior que queiram se fixar no Brasil ou estabelecer parcerias com os pesquisadores brasileiros. 
A história da cidade de Juiz de Fora sempre esteve pontuada por : movimentos migratórios, desde sua fundação. Tais movimentos, no passado, aconteceram com o intuito de suprir as necessidades de mão de obra na cidade (bem como de fugir de problemas encontrados na terra natal dos emigrados), que estava em franco desenvolvimento. Nos dias atuais, pode-se dizer que a economia da cidade gira em torno, principalmente, do contingente populacional e turístico atraído pela Universidade Federal de Juiz de Fora, fundada no ano de 1960. De acordo com o professor do Departamento de História da UFJF, Marcos Olender, em entrevista ao jornal Tribuna de Minas, em 27 de abril de 2012, "temos uma nova leva de visitantes de outras nacionalidades que se estabelecem temporariamente aqui [em Juiz de Fora], principalmente vinculados a programas de intercâmbio." Ainda segundo a referida reportagem, a UFJF contava, na época, com cerca de 120 alunos estrangeiros, sendo muitos europeus e africanos.

O que queremos dizer, ao apresentarmos essas questões, é que Juiz de Fora é uma cidade na qual os contatos linguísticos/culturais são intensos e frequentes. Isso pode colaborar para a formação de repertórios comunicativos cada vez mais diversificados, sem contar, é claro, o uso das mídias em geral.

No que tange às pichações, segundo uma reportagem publicada no Jornal Tribuna de Minas, na Rua São Mateus, Zona Sul da cidade, ao longo de 1,4 quilômetro, há uma a cada 20 metros em algum muro, parede ou portão. A realidade, segundo o jornal - e como podemos perceber ao circularmos pela cidade -, não é exclusiva daquela rua.

Como percebemos ao longo desta pesquisa, muitas dessas pichações e dos grafites realizados pela cidade se manifestam por meio de línguas outras que não o português. Apesar de tratarmos de um cenário específico, acreditamos que essa dinâmica intercultural reflete, em grande medida, o que tem ocorrido em outras partes do Brasil e do mundo, uma vez que há cada vez mais mudanças em termos de organização espacial - seja local ou translocal e/ou real ou virtual - e, consequentemente, em termos de diversidade cultural e de repertórios comunicativos.

Quanto ao grafite, há eventos, tais como mostras de grafite e encontros de grafiteiros, produzidos regularmente pela Associação Juizforana de Hip Hop (AJH2). Essa associação, sem fins lucrativos, foi criada em 2010. 


\section{Algumas diferenças entre grafites e pichações}

As cidades contemporâneas são marcadas por um grande número de variados estímulos visuais, o que inclui placas de estabelecimentos comerciais, outdoors, letreiros luminosos, banners e cartazes, placas indicativas de lugares, nomes de prédios, sinais de trânsito, propagandas políticas etc. Além disso, outros dois elementos estão presentes na paisagem linguística urbana: o grafite e as pichações.

De acordo com Shohamy e Gorter (2009, p. 1), enquanto a língua é utilizada pelos indivíduos para falar e ouvir, é também representada e exibida de forma escrita, algumas vezes por razões funcionais e outras com propósitos simbólicos. Essas são representações criativas que compõem a ecologia em contextos locais, globais e transnacionais, em línguas múltiplas.

É relevante destacar que reutilização dos espaços públicos através das pichações constitui um desafio à propriedade privada, uma vez que a ordem simbólica é subvertida com a apropriação do espaço do outro. Assim, tanto a pichação quanto o grafite (quando feito sem autorização) são considerados vandalismo e crime ambiental no Brasil, de acordo com a Lei 9.605/98 (Lei dos Crimes Ambientais), e a pena é detenção de três meses a um ano, e multa.

Para o site "Artistas na rua", a lei que criminaliza tanto a pichação quanto o grafite não considera as diferenças entre as duas formas de manifestação cultural. Isso porque "[...] o grafite brasileiro ganha cada vez mais espaço, inclusive fora do país, onde nossos artistas são chamados para montarem diversas exposições". Para os autores do site, "[...] ao contrário da pichação, o grafite é baseado em desenhos. Todas as letras e figuras utilizadas nas pinturas são pensadas, elaboradas, desenhadas e coloridas cuidadosamente, para que representem aquilo que o artista quer mostrar".

De acordo com Pennycook (2009, [s.p.]), o grafite pode ser considerado tanto parte de fluxos transculturais globais quanto práticas subculturais locais. Assim, apesar de essas manifestações artísticas e linguísticas existirem por todo o mundo, e de terem sua origem conhecida em Nova York (Estados Unidos), na década de 1970, elas ganham contornos locais, de acordo com as características de determinada região e de seus idealizadores.

Nesse sentido, entrevistamos três grafiteiros (ex-pichadores) da

7 Disponível em: http://www.artistasnarua.com.br/textos/grafite-e-pichacao. Acesso em: 11 jul. 2015. 
: cidade de Juiz de Fora, buscando compreender como esses dois conceitos e : suas diferenças são entendidos por eles. As entrevistas foram feitas através de uma rede social e os nomes foram modificados, a fim de preservarmos a identidade dos participantes.

O primeiro informante foi Rodrigues (30), que atuou na cena grafitepichação por quase 12 anos, de 2001 até meados de 2012. De acordo com o entrevistado, grande parte de suas pinturas eram feitas de forma ilegal. "Com o tempo fui criando uma consciência artística maior e ficando mais exigente com minhas pinturas, isso me levou a procurar lugares mais calmos ou legalizados para pintar" (RODRIGUES, 2015). Ao falar sobre sua intenção ao fazer uma pichação, Rodrigues (30) disse:

[...] No meu caso, começou como revolta [fase das pichações], mais [sic] logo se converteu em pura vontade de fazer sempre um trabalho melhor do que o anterior. Com o tempo, pude conhecer escritores de graffiti de outras cidades e países, cada um com um estilo de pintura, alguns muito bons, e isso acendeu em mim uma vontade muito grande de fazer parte disso como um dos melhores, o que me levou a estudar muito desenhos e manter sempre um compromisso com a qualidade de meus trabalhos (RODRIGUES, entrevista concedida em 19 jan. 2015).

Silva (36), por sua vez, atua como grafiteiro há 10 anos em Juiz de Fora. Hoje, é reconhecido como artista e faz trabalhos voluntários ligados à arte do grafite. Para ele, a intenção do grafiteiro é "estar evoluindo e contribuindo com a cultura". O entrevistado não falou sobre a questão das pichações, mas considerando suas colocações, é possível perceber que separa grafite (arte) e pichação (com conotação negativa no meio social), considerando-se apenas como grafiteiro.

Júnior (40) atua desde 1997, antes como pichador e, atualmente, como grafiteiro. São 18 anos na cena grafite-pichação de Juiz de Fora. De acordo com ele, "[...] os tags "pichação" ficam no início da cultura, para depois saber que a atividade é responsável e legítima" (JÚNIOR, entrevista concedida em 20 jan. 2015).

Dessa forma, podemos dizer que a pichação é a primeira manifestação de um indivíduo que busca demonstrar rebeldia, transgressão às regras 
impostas pela sociedade através do livre pensamento e da livre expressão em muros que são propriedade privada de outro indivíduo. A intenção : é organizar-se em grupos denominados "crews", cujos nomes são suas assinaturas, que competem em quantidade e qualidade de pichações. A qualidade está ligada também a questões de risco, i.e., lugares mais altos ou mais perto da polícia, por exemplo.

O grafite, por sua vez, é uma manifestação artística, cujos autores são contratados, em sua maioria, para realizar seus trabalhos. Há uma organização local e translocal desses artistas, que por vezes criam associações e se comunicam com artistas de outros lugares, até mesmo de outras partes do mundo.

\section{Fragmentos linguísticos encontrados em grafites e pichações pela cidade}

De acordo com Kroon, Jie e Blommaert (2011, p. 5), “os significados são efeitos da mobilidade", essa que faz parte de um mundo globalizado. Ainda para os autores, os efeitos da globalização têm formado meio ambientes sociolinguísticos altamente complexos, povoados por pessoas com diferentes experiências e trajetórias, diferentes formas e graus de acesso a recursos sociolinguísticos e semióticos e a frames para interpretação (KROON, JIE \& BLOMMAERT, 2011, p. 14).

Nesse sentido, é importante, antes de analisarmos as fotografias tiradas pela cidade, considerar que todos os signos apontam para trás (i.e. para seu produtor e para as condições de produção) e para frente (i.e. para o público e para as consequências pretendidas) (KROON, JIE \& BLOMMAERT, 2011, p. 5). O produtor, no caso das pichações, é um indivíduo que busca rebelar-se contra algo, contra tipos de opressão, e as condições de produção remetem à clandestinidade. Talvez por isso, em sua maioria, as pichações sejam frases diretas ou apenas uma palavra (por vezes, a assinatura do "crew"). O que nos surpreende, nesta pesquisa, é que grande parte dessas pequenas frases ou palavras apresentam recursos de línguas estrangeiras, o que nos leva à ideia de restrição de público. Apenas aqueles que conhecem aquelas expressões na língua utilizada terão a compreensão daquilo que está escrito. No entanto, mesmo sem a compreensão exata da expressão pichada, o indivíduo tem acesso à intenção do produtor: a oposição ao sistema.

Essas inscrições em língua estrangeira são lidas por pessoas dos 
mais diversos tipos, por todos aqueles que trafegam pela cidade, desde : os indivíduos que são contra essas manifestações (população, polícia etc.) e a favor (os membros de outros crews, por exemplo). Com isso, como acreditamos, é possível que essas manifestações em língua estrangeira, muitas vezes, contribuam para a formação do repertório comunicativo dos indivíduos passantes.

Assim, a seguir, apresentamos e analisamos algumas fotografias de pichações e grafites tiradas pela cidade de Juiz de Fora, as quais demonstram efeitos da globalização e da superdiversidade por meio de recursos linguísticos de diferentes línguas políticas presentes no espaço pesquisado.

A figura (1), a seguir, foi tirada na Zona Sul de Juiz de Fora:

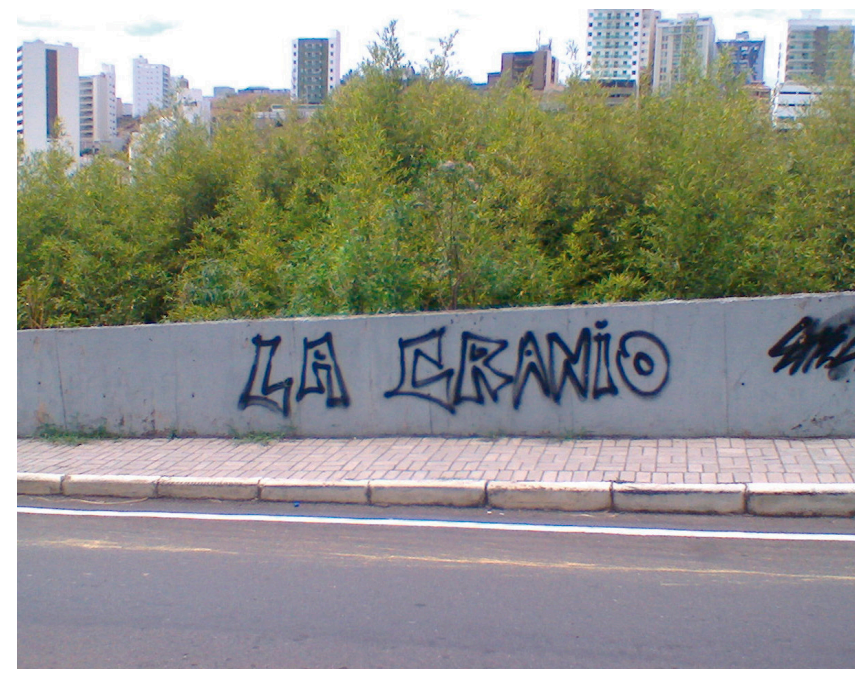

Figura (1): Rua Luiz Gonzaga de Araújo Evangelista, Bairro Estrela Sul, 05 out. 2014

Fonte: fotografia tirada pela autora.

Neste caso, notamos a presença de recursos do italiano. Conforme acreditamos, possivelmente esses recursos são uma assinatura de um "crew" ou de um único pichador. O significado da expressão a priori é "o crânio" (caveira), mas sabemos que os significados ocultos, aqueles aos quais não temos acesso sem o conhecimento do produtor ou de seu grupo - sem esse reconhecimento compartilhado das partes engajadas na interação -, transcendem essa interpretação. Isso porque, a partir do momento em que 
os signos do italiano se moveram para um contexto diferente, os significados também se deslocaram e adquiriram novos contornos. Essa mesma questão : pode ser considerada para as demais fotografias disponibilizadas neste trabalho, uma vez que todas estão ligadas à mobilidade dos signos.

A figura (2), a seguir, foi tirada na Zona Norte da cidade:

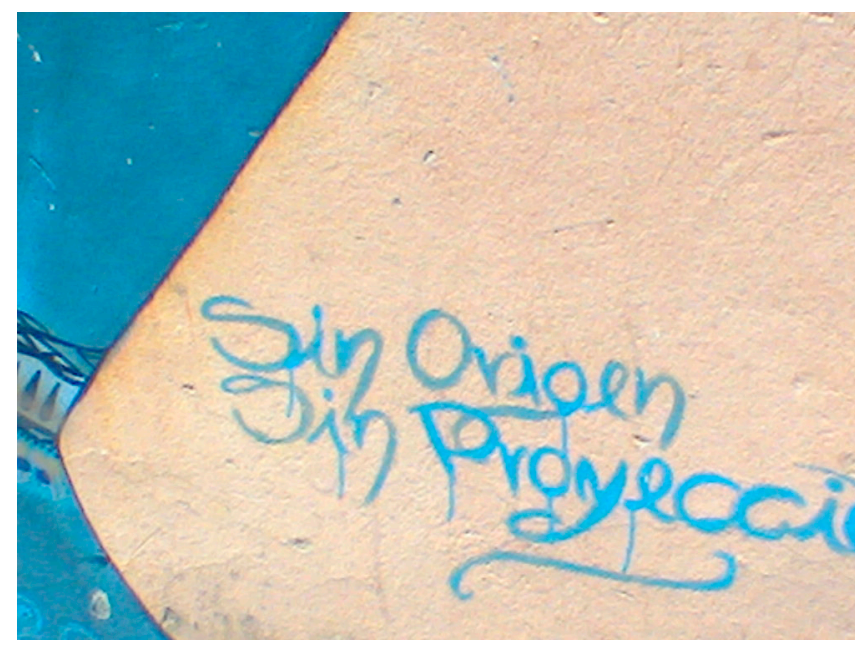

Figura (2): Rua Antonio Armando Pereira, Barbosa Lage, 11 jan. 2015

Fonte: fotografia tirada pela autora.

Esta inscrição, acompanhada de um grafite feito em um muro de uma escola, mostra o uso de recursos do espanhol, que fazem parte do repertório comunicativo do escritor. Os termos "sin origen" ("sem origem") e "sin proyección" ("sem projeção") remetem ao caráter marginal do grafite, uma vez que grande parte dos artistas não tem reconhecimento (ou é confundida com pichadores) e dispõe de pouco espaço para sua arte na sociedade.

A figura (3), por sua vez, foi tirada na Zona Oeste da cidade: 


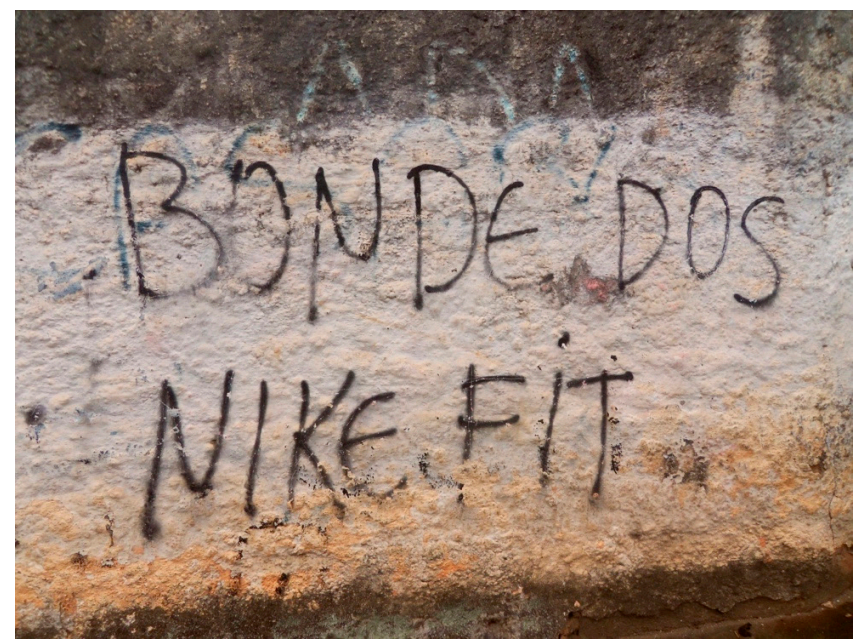

Figura (3): Rua Pedro Henrique Krambeck, Jardim Casablanca, 15 out. 2014

Fonte: fotografia tirada pela autora.

Neste caso, percebemos como os significados globais ganham contornos locais (PENNYCOOK, 2009). A palavra "bonde" é uma construção social brasileira, através da qual se tem a noção de "grupo que gosta do ritmo funk". A palavra é estigmatizada e muitas vezes ligada aos frames "violência" e "marginalidade". "Nike", por sua vez, remete a uma marca muito conhecida no mundo todo e voltada para a elite. A palavra "fit" vem do inglês e seus significados literais são "servir", "pertencer a" ou "ser aceito". Há uma vertente da marca que também é chamada "Nike Dri-Fit”, voltada para a prática de esportes. Ambas as ideias criam um paradoxo entre o que é marginal (o ritmo funk) e o que é da elite (Nike ou Nike Dri-Fit). Essa mistura de recursos não permite um significado a priori, uma vez que aponta para um produtor e para uma situação de produção desconhecida por aqueles que não fazem parte do grupo. 
A figura (4), a seguir, foi tirada na Zona Norte da cidade em questão

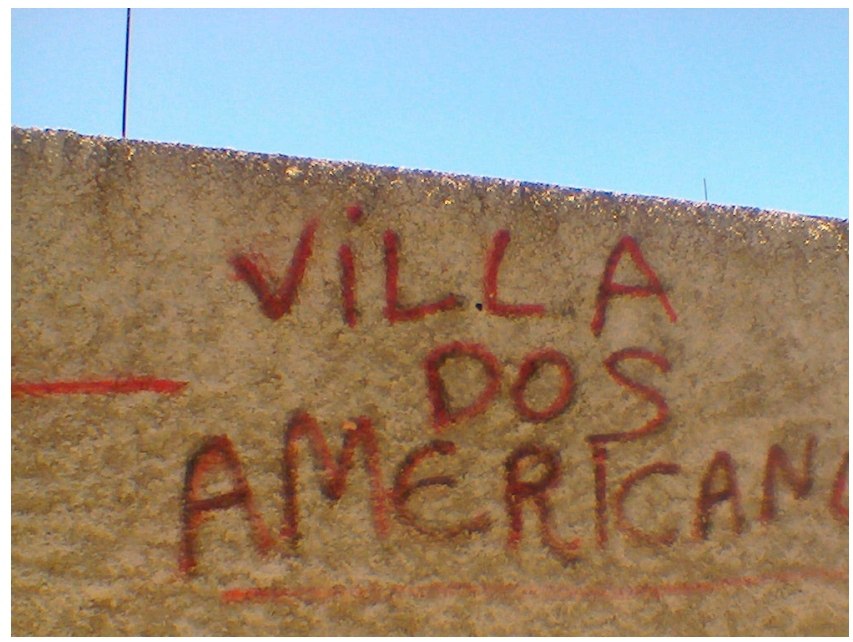

Figura (4): Rua Constância Vidal, Jóquei Clube, 11 março de 2015 Fonte: fotografia tirada pela autora.

Esta foto foi tirada em uma região considerada marginalizada da cidade. No entanto, podemos notar o quanto a globalização está presente neste contexto, através da lookalike language (BLOMMAERT, 2010). Neste caso, há a palavra "Villa", com duas letras "l", que pode ter recebido influências de recursos do italiano, do francês, do inglês etc.. Se pensarmos na palavra "americanos", que pode remeter aos norte-americanos e ao uso da língua inglesa (assim como o uso da apóstrofe), temos, mais uma vez, um significado voltado para a elite. A palavra "villa" remete a residências luxuosas no contexto inglês, de campo ou de praia. Outro significado é casa de subúrbio. A interpretação depende do produtor, apesar de termos acesso às condições de produção. A apóstrofe, por sua vez, foi utilizada de forma diferente do inglês padrão. No entanto, quando pensamos na estrutura "Villa dos americano's", é possível inferir que a intenção do produtor pode ter sido indicar posse, o que ficou redundante com "dos", do português brasileiro. Essa "sopa" de palavras (BLOMMAERT, 2010) mostra como recursos do inglês foram movidos para o contexto do bairro juzforano "Jóquei Clube", adquirindo significados locais. 
A figura (5), a seguir, mostra como o lookalike está presente mais uma : vez. A fotografia foi tirada na Zona Sul.

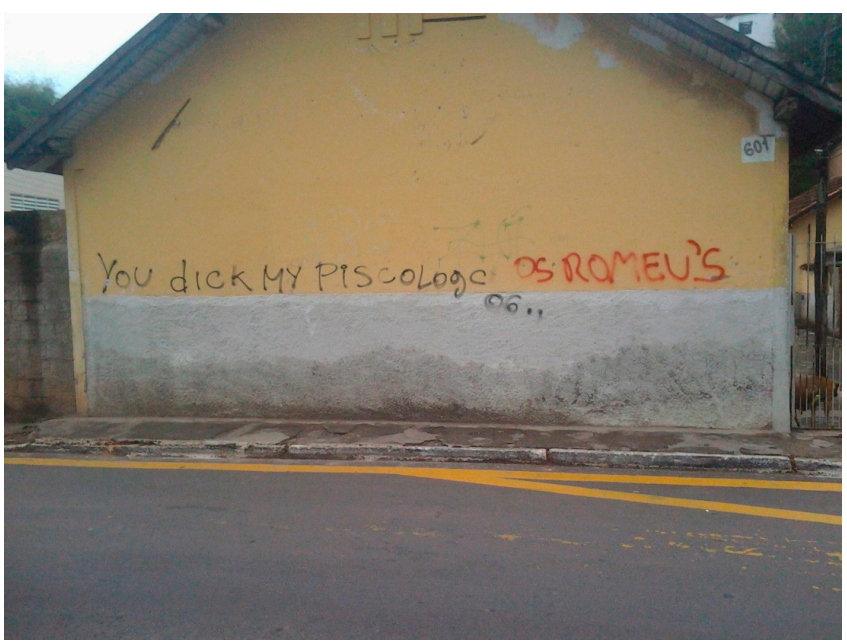

Figura (5): Av. Ibitiguaia, Santa Luzia, 24 nov. 2014 Fonte: fotografia tirada pela autora.

A pichação foi assinada pelo grupo "Os Romeu's". Os termos "You dick my" são do inglês, formando uma frase em lookalike language com o termo em português "piscologo" (cuja grafia está diferente do padrão "psicólogo"). A frase parece uma "sopa de palavras", cujo significado parece ser conhecido apenas pelo(s) produtor(es). Além disso, a apóstrofe em "Romeu's" também sugere o uso de um recurso de língua inglesa, apesar de ter sido utilizado fora do padrão. Ao apresentar essa fotografia, buscamos demonstrar a mobilidade dos signos, cujas formas viajam, muitas vezes, sem problemas, enquanto outros recursos (como indexicalidade, significados, valor social etc.), acabam recebendo inovações no contexto para o qual se moveram.

\section{CONSIDERAÇÕES FINAIS}

Em uma sociedade marcada por transformações irregulares e imprevisíveis, as línguas têm se tornado cada vez mais fragmentadas e móveis. O que parece existir, tal como defendemos neste trabalho, é um complexo de processos sociolinguísticos se desenvolvendo de diferentes formas, velocidades e intensidades, modificando a paisagem linguística do 
mundo. Por isso, atualmente, devemos estudar uma "sociolinguística da mobilidade", a partir da qual se considera que os recursos são móveis, assim : como as pessoas.

Nesse sentido, noções como território linguístico e monolinguismo não são mais uma realidade, se é que já foram um dia. O que vemos é uma realidade de contatos linguísticos cada vez mais dinâmicos, principalmente nos centros urbanos. Dessa forma, neste trabalho, discutimos questões relacionadas a manifestações linguísticas presentes em pichações e grafites na cidade de Juiz de Fora/MG, com o intuito de mostrar a presença de formas (i.e., de fragmentos de línguas políticas) que se moveram e receberam novos contornos - em termos de indexicalidade, valor social, significados etc. - em um novo contexto.

Assim, buscamos, por meio de um cenário específico, refletir, em grande medida, o que tem ocorrido em outras partes do mundo, uma vez que há cada vez mais mudanças em termos de organização espacial e, consequentemente, em termos de diversidade cultural e de repertórios comunicativos.

\section{REFERÊNCIAS BIBLIOGRÁFICAS}

BLOMMAERT, Jan. Ethnography, Superdiversity and Linguistic Landscapes: Chronicles of Complexity. Bristol, UK: Multilingual Matters, 2013.

BLOMMAERT, Jan. Lookalike language. English Today, n. 2, v. 28, 2012. p. 60-62.

BLOMMAERT, Jan. The Sociolinguistics of Globalization. New York, USA: Cambridge University Press, 2010.

CARVALHO, Nathália. Uma pichação a cada 20m na São Mateus. Jornal Tribuna de Minas, 17 de dezembro de 2014. Disponível em: http://www. tribunademinas.com.br/uma-pichacao-a-cada-20m-na-sao-mateus. Acesso em: 28 março 2012.

GRABER, Kathryn E. On the Disassembly Line: Linguistic Anthropology in 2014. American Anthropologist, v. 117, n. 2, 2015. pp. 350-363. 
IBGE. Censo demográfico 2010. Disponível em: http://www.ibge.gov.br/ : cidadesat/topwindow.htm?1. Acesso em: 28 março 2012.

JÚNIOR. Depoimento [jan. 2015]. Entrevistadora: Mariana Schuchter Soares. Juiz de Fora, 2015. 1 arquivo, escrito. Entrevista 003/2015 concedida para elaboração da tese de doutorado da entrevistadora.

KROON, Sjaak; JIE, Dong. \& BLOMMAERT, Jan. Truly Moving Texts. Tilburg Papers in Culture Studies. 2011. Disponível em: https://www. tilburguniversity.edu/upload/9337fbc1-3723-474c-bf53-c9e457562bb2_ tpcs\%20paper3.pdf. Acesso em: 23 jun. 2015.

MICHELOTTI, Denise. Arte em vitrais: a salvaguarda, a extroversão e a sociomuseologia. 2011. Dissertação (Mestrado em Museologia). Universidade Lusófona de Humanidades e Tecnologias, Lisboa, Portugal, 2011. $118 \mathrm{f}$.

PENNYCOOK, Alastair. Landscapes and the Transgressive Semiotics of Graffiti. In: SHOHAMY, E. \& GORTER, D. (Orgs.). Linguistic Landscape: expanding the scenery. New York, USA: Routledge, 2009.

RAJAGOPALAN, Kanavillil. Vencer barreiras e emergir das adversidades com pleno êxito, sempre com o pé no chão. In: LIMA, D. C. de. Inglês em escolas públicas não funciona: uma questão de múltiplos olhares. São Paulo: Parábola, 2009. pp. 55-65.

RODRIGUES. Depoimento [jan. 2015]. Entrevistadora: XXXXXXXX. Juiz de Fora, 2015. 1 arquivo, escrito. Entrevista 002/2015 concedida para elaboração da tese de doutorado da entrevistadora.

RUBDY, Rani \& ALSAGOFF, Lubna. (Orgs.). The Global-Local Interface and Hybridity: Exploring Language and Identity. Bristol, UK: Multilingual Matters, 2014.

RYMES, Betsy. Communicative repertoire. In: LEUNG, C; STREET. B. V. (eds.) The Routledge Companion to English Studies. Routledge, 2014. Disponível em: https://upenn.academia.edu/BRymes. Acesso em: 01 set. 2014. 
SANGLARD, Fernanda. Juiz de Fora é a segunda de Minas Gerais em número de imigrantes. Jornal Tribuna de Minas, 27 de abril de 2012. Disponível : em: http://www.tribunademinas.com.br/cidade/jf-e-segunda-de-mg-emnumero-de-imigrantes-1.1082427. Acesso em: 25 nov. 2013.

SILVA. Depoimento [jan. 2015]. Entrevistadora: Mariana Schuchter Soares. Juiz de Fora, 2015. 1 arquivo, escrito. Entrevista 001/2015 concedida para elaboração da tese de doutorado da entrevistadora.

VERTOVEC, Steven. Super-diversity and its implications. Ethnic and Racial Studies, 29 (6), 2006. 